\title{
Acute coronary syndrome
}

\section{Sandra Franjić, Zrinka Švec, Maja Jurec*}

University Hospital „Sveti Duh", Zagreb, Croatia
RECEIVED:

February 12, 2020

ACCEPTED:

February 22, 2020

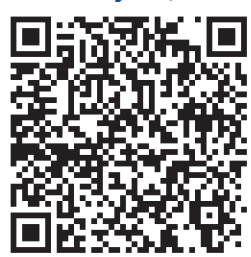

KEYWORDS: acute coronary syndrome, nurse, cardiac catheterization laboratory

CITATION: Cardiol Croat. 2020;15(3-4):65. | https://doi.org/10.15836/ccar2020.65

*ADDRESS FOR CORRESPONDENCE: Maja Jurec, KB Sveti Duh, Sveti Duh 64, HR-10000 Zagreb, Croatia. / Phone: +385-91-975-64-93 / E-mail: majajurec0908@gmail.com

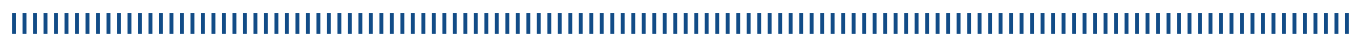

In Croatia and throughout the world cardiovascular diseases represent a great public health problem as they are most common among diseases and the leading cause of death. Annually about 4 million people in Europe dies of cardiovascular disease (45\% of all deceased). Acute coronary syndrome (ACS) is an acute complication of heart and blood vessels disease and is most commonly caused by atherosclerosis or coronary thrombosis. Types of ACS are unstable angina, ST-elevation myocardial infarction (STEMI) and non-ST-elevation myocardial infarction (NSTEMI). ${ }^{1}$ The purpose of this paper is to describe the role of the nurse in caring for patients suffering from acute coronary syndrome.

Nurses in cardiac catheterization labs have gained immense knowledge through schooling and work. The role of nurses is not only participating in teamwork while caring for patients with ACS in cardiac catheterization labs, but also monitoring patients during their hospitalization. Teamwork is of great importance from the very beginning of the intervention procedure when blood vessels are opened, as well as during hemodynamic and rhythmological monitoring in the operating room. What is also important is the support given to the patient in the cardiac catheterization lab during the intervention when our patients are awake and fear for their life. Inasmuch as we are with them since the acute phase it is important to continue to support them during the entire hospitalization and throughout the following rehabilitation program. Good patient rehabilitation increases their chances of survival in case of reiterated coronary disease complications. Mortality rates for cardiovascular disease have been reduced in developed countries due to the increased number of educational programs for people, improved prehospital care, as well as improved monitoring and treatment methods.

Continuous systemic education of contemporary methods of treatment are essential prerequisites of timely acute coronary syndrome treatment. 